\title{
Emissions in real urban traffic conditions as a determinant of shaping sustainable urban development
}

\author{
M. Jacyna ${ }^{1} \&$ J. Merkisz ${ }^{2}$ \\ ${ }^{1}$ Warsaw University of Technology, Poland \\ ${ }^{2}$ Poznan University of Technology, Poland
}

\begin{abstract}
The paper presents an approach to analyse the impact of emissions in real urban traffic conditions on the shaping of a sustainable transport system. The authors show that developing a sustainable transport system will permit a wide range of research, experimentation and simulation of apportioning traffic streams on the transport network. Some aspects of estimating the level of harmful emissions generated by the transport network users across the country or the particular areas are presented. The paper presents the part of research in the "EMITRANSYS" project implemented by the Faculty of Transport in Warsaw University of Technology and the Poznan University of Technology.

Keywords: sustainable transport, ecological urban transport, EMITRANSYS.
\end{abstract}

\section{Introduction}

A sustainable transport system is a system that ensures availability of transport services and mobility of all inhabitants of a given area in a safe and environmentally friendly way, contributing to the economic development and wealth of society. In that case, a sustainable transport system possesses all features of a transport system [1-5]. Designing such a system, we have to take into consideration economic, ecological and social aspects.

Economic aspects connected to develop the transport system most efficiently at given costs or to obtain a given efficiency at the lowest possible cost. Additionally, it is very important to reduce the negative impact of the functioning transport system on the environment, such as exhaust emissions or noise levels. 
A reduction in the exhaust emissions may be achieved by increasing the smoothness of the traffic flow and a reduction of the number of motor vehicles in city centers, integration of with other modes of transport within the Park\&Ride, Park\&Go systems or increasing road transport the quality and availability of transit public. The social functioning of transport system may be realized through a developed network of public transit or a properly developed road infrastructure [1-7].

So developing sustainable transport system is making the transport system most useful for society by reacting to the transport needs that will guarantee access to all destinations from one side. From the other side developing transport system means determining the relationship between forecasted transport tasks, its equipment and the cost of tasks fulfilment by this system.

Study on the influence of different strategies of the management body such as transport policy or strategy of transport services providers shaping the transport network infrastructure is subject to the disposal by the authority with appropriate research tools required to conduct the research. There must be a generalization of the traffic flow distribution model in the transport system in such a way as to permit sufficient assessment of the degree of adjustment of the characteristics of the infrastructure for ongoing transport tasks, taking into account not only the criteria of technical or economic but primarily environmental.

Modelling ecological transport system, and subsequently its simulating, requires relevant data about emission in transport. Road transport is a main source of pollution, so it is well worked on in the literature (e.g. [8-10]). For $\mathrm{NO}_{2}$, road traffic is of special relevance because it typically accounts for the major proportion of $\mathrm{NO}_{\mathrm{x}}$ emissions, and hence of $\mathrm{NO}_{2}$ concentrations $[9,11,12]$.

Most of the emission factors used by the emission inventories to quantify traffic contribution upon total emissions originate from laboratory measurements carried out according to specific measure and driving protocols (e.g. [24]).

A GIS-based transport add-on environmental modelling system designed to evaluate the environmental consequences of road traffic in urban areas is presented in the work [1]. The authors in the article [21] implement the road traffic assignment model, in conjunction with an air pollution dispersion model, to the urban road network of selected city.

In the case of above mentioned very important is developing the methodology of exhaust emission measurements in the development of sustainable road transport. In the works $[1,9,10,12]$ authors analyze researches bases on realtime experiments and long-term on-board analyses to gain universal emission characteristics for different traffic conditions including cold starts, long and short trips or congestion. Their research is done to answer the question of real emission levels compared with EURO standards. EMITRANSYS project adapt this methodology to obtain broad vehicles characteristics opportunely for simulation $[4,10,13]$.

The intention of the authors was to determine the impact of driver behavior on the human environment and an indication of the impact of his driving style on the environmental and energy aspects of the vehicle use. Therefore in this article are presented results of tests of toxicity of exhaust gases (passenger car), 
conducted in road conditions. The tests provided information about emission of harmful gases in the dynamic conditions of urban traffic. The test were conducted in order to initial verify the influence of driving style on the emission of carbon dioxide and on the fuel consumption by the tested vehicle [6].

\section{Sustainable transport system model}

The model of sustainable transport system should take into account requirements of physical transport processes $[1,7]$ :

- lasting objects: roads, service stations for passenger and freight transport with specified characteristics;

- vehicles - means of transport that use transport infrastructure;

- people forming crew of transportation system, which use technical equipment of the system for the movement of passengers and cargo;

- organizational system ensuring the correct use of technical equipment of transport.

Model ecological transport systems must have properties allowing studies on modal interaction with regard to the level of emissions. So in this regard it has been defined, taking into account the following basic elements:

- set of types of vehicles used to perform transport tasks, described as records of database;

- structure of transport network depicting links between origin, intermediate, and destination points for passenger and cargo streams;

- characteristics of network elements representing actual properties of vehicles and transport connections (characteristics derived from existing databases, especially characteristics assigned to nodes of the network resulting from the treatment of vehicles, where mode of transport is changed, and characteristics assigned to edges of network resulting from movement of vehicles);

- size of transport tasks identified at the input to the system (demand for transport services reported by purchasers of services);

- organization conceived as a way to carry traffic via the transport network from input places to output places with regard to emission levels, stock of means of transport, infrastructure condition and economic conditions.

Assuming that a set of types of vehicles is marked as ST, structure of transportation system is marked as GE, a set of characteristics of means of transport and structural elements is marked as $\mathbf{F E}$, matrix of tasks performed by system is marked as QE, traffic organization on the network is marked as $\mathbf{O E}$, then Model Environmentally friendly Transportation System (MEST) can be written as an ordered five [2]:

$$
\text { MEST }=\langle\text { ST, GE, FE, QE, OE }\rangle
$$

The individual components of the model described in detail in [2]. Each st vehicle type was characterized by a vector of parameters of technical and technological, environmental and economic form:

where:

$$
\mathbf{v}(\mathbf{s t})=[r s p(s t), n e u(s t), q(s t), m(s t), c(s t), e m(s, s t)]
$$


$\begin{array}{lll}r s p(s t) & - & \text { type of engine of } s t \text { vehicle type, } \\ n e u(s t) & - & \text { type of EURO standard of } s t \text { vehicle type, } \\ q(s t) & - & \text { load / capacity of } s t \text { vehicle type, } \\ m(s t) & - & \text { type of transport (passenger, cargo) of } s t \text { vehicle type, } \\ c(s t) & - & \text { unit cost of transport of } s t \text { vehicle type, } \\ e m(s, s t) & - & \text { unit emissions of } s \text {-th harmful compound type for } s t \text { vehicle. }\end{array}$

Database of transport vehicles BST was written as a vector of three elements, $\mathbf{B S T}=[\mathbf{S}, \mathbf{S T}, \mathbf{v}(\mathbf{s t})]$. The structure of the transport system in the model MEST was presented using graph $\mathbf{G E}, \mathbf{G E}=\langle\boldsymbol{W E}, \boldsymbol{L E}\rangle$, where the set $\boldsymbol{W E}$ is a set of transport nodes numbers, which in the real transport network are points of creation and disappearance of streams of passengers, origins and destinations of cargo and cargo handling or passengers intermediate points (for example, transhipment points, logistics centres, intermodal transport terminals, etc.), while $\boldsymbol{L E}$ is a set of real transport connections [2].

Database characteristics of the transport vehicles and structural elements of the transport system BFE was written as a vector: BFE=[FLE, FWE, FSP], where FLE is a data base with connections, FWE - data base with nodes and FSP is a data base with transport vehicles. A set of characteristics of elements provides specifications of vehicles of given types (i.e. emission standards $n e s(n(s t), s t)$ and average unit cost of operation dependent on travelled distances), particular nodal components of system servicing, generating or taking away material and passenger flows, as well as technical parameters of transport links, such as length $d\left(i, i^{\top}\right)$, section speed limits $v\left(i, i^{\top}\right)$, flow capacities $q\left(i, i^{\top}\right)$, and other technical parameters $[1,7]$.

The size of transport tasks in EMITRANSYS model was presented as a twoelement vector $\boldsymbol{Q E}, \boldsymbol{Q E}=[\mathbf{X} \mathbf{1}, \mathbf{X} 2]$, where $\mathbf{X} \mathbf{1}$ is a matrix of demand for cargo transport, and $\mathbf{X} \mathbf{2}$ is a matrix of demand for passenger transport [1, 7].

The influence of engine type, Euro standard and the length of travelled $p$-th path in relation $(a, b)$ on emission is described by coefficients $\psi(s, s t, n e u(s t)$, $r s p(s t), p, a, b)$. After projection, they take a form of $\psi a(s, s t, p, a, b)$.

When model parameters are defined as above, the problem of developing proecological transport system is reduced to searching for the values of decision variables $x t(p, a, b, s t)$ and $x p(p, a, b, s t)$ constituting numbers of $s t$-th type vehicles performing freight and passenger transport tasks on $p$-th paths in relations $(a, b)$. Then the criteria function:

$$
\begin{gathered}
\forall s \in \boldsymbol{S} \sum_{s t \in \boldsymbol{S} \boldsymbol{T}} \sum_{\left(i, i^{\prime}\right) \in \boldsymbol{L} \boldsymbol{E}} \sum_{(a, b) \in \boldsymbol{E}} \sum_{p \in \boldsymbol{P}_{i i^{\prime}}^{a b}}[x t(p, a, b, s t)+x p(p, a, b, s t)] \cdot \\
\cdot d\left(i, i^{\prime}\right) \cdot \operatorname{ema}\left(s, s t, i, i^{\prime}\right) \cdot \psi a(s, s t, p, a, b) \longrightarrow \min
\end{gathered}
$$

Feasible solutions must keep some constraints like all transport demand must be satisfied or total number of means of transport used for task realization and not exceeding the number of disposed vehicles. Of course, very important are constraints connected with capacity of transport links (sections) can't be exceeded and area/section access restrictions according to pollution or acceptable levels of harmful compounds emission can't be exceeded. 


\section{The harmful emission measurements under actual conditions of operation}

Sustainable road transport systems must consider environmental issues, so reliable vehicle exhaust emission data are extremely important. In the currently applicable homologation tests in the vehicle category of PC and LDV the parameters of operation of the engines are much different from the actual intraffic parameters $[4,6,12]$. During the measurement and analysis of the exhaust emissions from road transport the key factor is the specialized measurement equipment from the PEMS group (Portable Emission Measurement System). In order to determine the on-road or unit exhaust emissions we must know the mass flow rate of the exhaust gases. For this purpose exhaust mass flow meters are used.

In the work $[1,4,7,9]$ the vehicle emission index (given exhaust component) has been defined as times increase (or decrease) emissions in real traffic conditions in relation to the certification test. Such indicator, for the harmful compound, defined as follows:

$$
\forall s \in \boldsymbol{S} \quad k(s)=\frac{E_{\text {real }}(s)}{E_{\text {test }}(s)}
$$

where:

$s \quad-$ exhaust component for which the emission index was determined, $E_{\text {real }}(s)$ - emission rate under actual traffic conditions $([\mathrm{g} / \mathrm{s}])$,

$E_{\text {test }}(s)$ - emission rate measured in the NEDC test $[\mathrm{g} / \mathrm{s}]$ or other tests such as those for heavy-duty vehicles (ETC, WHTC) (lub ([g/s]).

The emission rate under actual traffic conditions can be calculated using the characteristics of the vehicle operating time distribution $u(a c, V)$ and the characteristics of the emission rate for an $s$-th exhaust component $e(a, v)$ expressed in grams per second:

$$
\forall s \in \boldsymbol{S} \quad E_{\text {real }}(s)=\sum_{a c \in A C} \sum_{V \in \boldsymbol{V}} u(a c, V) \cdot e(s, a c, V)
$$

where:

$u(a c, V)$ - the share of the working time of the vehicle, $e(s, a c, V)$ - emission intensity for $s$-th harmful compound $([\mathrm{g} / \mathrm{s}])$.

The on-road emission index of a given exhaust component can assume values from the range $\langle 0, \infty)$. This means that if the on-road emission from a vehicle does not exceed the normative values, the index has a value less than 1 and when the normative value is exceeded the index is greater than 1 and when the actual emissions are equal to the normative one the index equals $1[1,6]$.

The graphs in figures 1-3 show the extent of changes of the emission index for which the normative limit is met for each exhaust component (dotted line). Despite high momentary variability of the emission index its 'incrementing value' is characterized as follows:

- for carbon monoxide (fig. 1) - a very abrupt growth during engine start and then a reduction of its value; a satisfactory reduction of the emission is 
obtained within the limits of the required standard for both the Euro 4 and Euro 5 vehicles; the index values are comparable for the tested vehicles;

- for hydrocarbons (fig. 2) - the course of the index changes is similar to carbon monoxide, yet the Euro 4 vehicle needed a shorter distance (approximately $2 \mathrm{~km}$ ) to reach the index value below 1;

- for nitric oxides (fig. 3) - no normative requirements have been met - this mainly results from the difference of the engine operation in the NEDC test and that under actual traffic conditions.
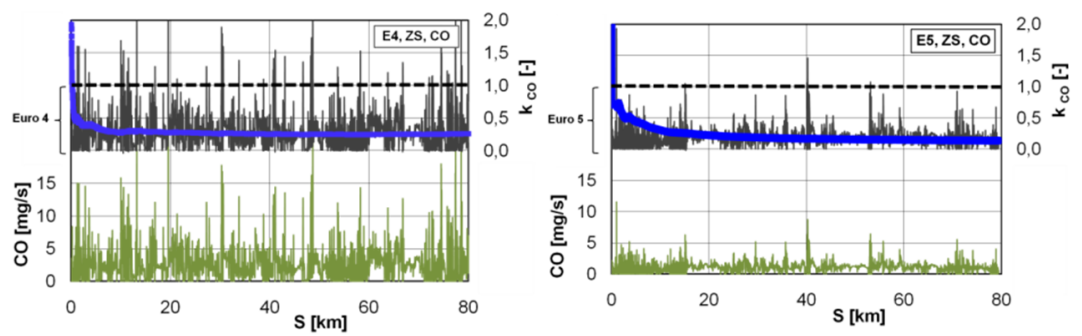

Figure 1: The values of the emission rate and indexes of on-road emission for passenger vehicles compliant with Euro 4 and Euro 5 emission standard for carbon monoxide $[1,2]$.
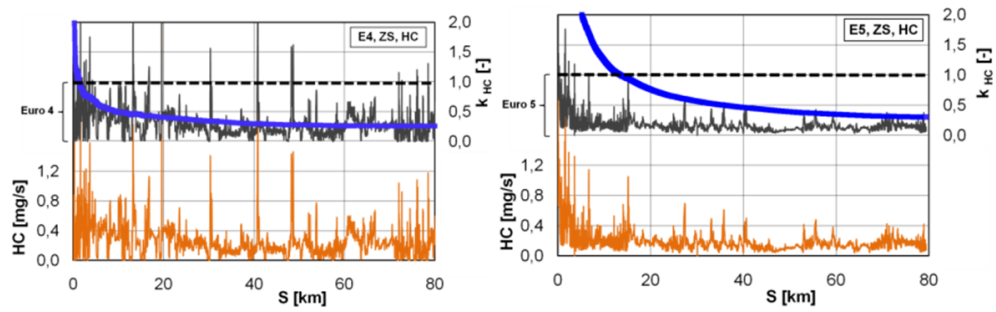

Figure 2: The values of the emission rate and indexes of on-road emission for passenger vehicles compliant with Euro 4 and Euro 5 emission standard for hydrocarbons $[1,2]$.
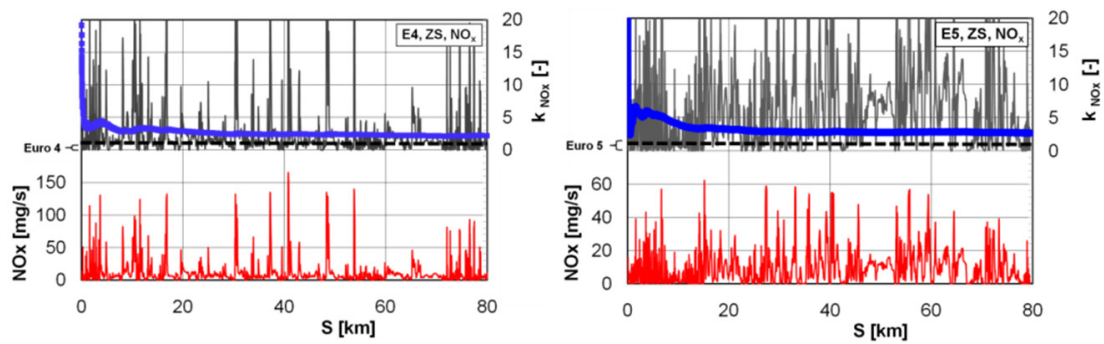

Figure 3: The values of the emission rate and indexes of on-road emission for passenger vehicles compliant with Euro 4 and Euro 5 emission standard for nitric oxides $[1,2]$. 
In the work [10] the authors show that gasoline-powered vehicles emit twice the mass of carbon monoxide and hydrocarbons, while four times less nitrogen oxides and particulate mass. The mathematic formula of emissions from vehicles powered gasoline and diesel can be as follows:

$\forall s \in \boldsymbol{S}, \forall n e \in \boldsymbol{N} \boldsymbol{E}, \quad \forall r s \in \boldsymbol{R S}$

$E(s, n e u, r s)=\alpha(s, n e u, r s) V^{3}+\beta(s, n e u, r s) V^{2}+\gamma(s, n e u, r s) V+\delta(s, n e u, r s)$

where: $\alpha(s, n e u, r s), \beta(s, n e u, r s), \gamma(s, n e u, r s), \delta(s, n e u, r s)$ - coefficients, $n e$ - number of standard Euro, rs-engine type.

The values of the exhaust emission indexes for passenger vehicles were determined based on the performed tests under actual traffic conditions. For the determination of the emission indexes for the outstanding categories the authors adopted the results of earlier work carried out by the research team with the Chair of Combustion Engines at Poznan University of Technology [4, 9, 10].

For the category of low emission vehicles the emission indexes assume values much greater than 1 in the initial driving phases but then they decrease to a value of several per cent of the value set forth in the emission standard (this dependence is the case for the emission of carbon monoxide and hydrocarbons). Contrary to the presented scheme is the course of the emission index for nitric oxides: it decreases its value, but it does not reach the level set forth in the emission standard. For this reason under actual traffic conditions the emission of nitric oxides is several times above the admissible limit - this dependence was confirmed in the tests of heavy-duty vehicles and city buses. For the rest of the vehicles of different emission categories the emission index curves $k=f(S)$ were determined as dependent on the distance covered by the vehicles (Fig. 4).

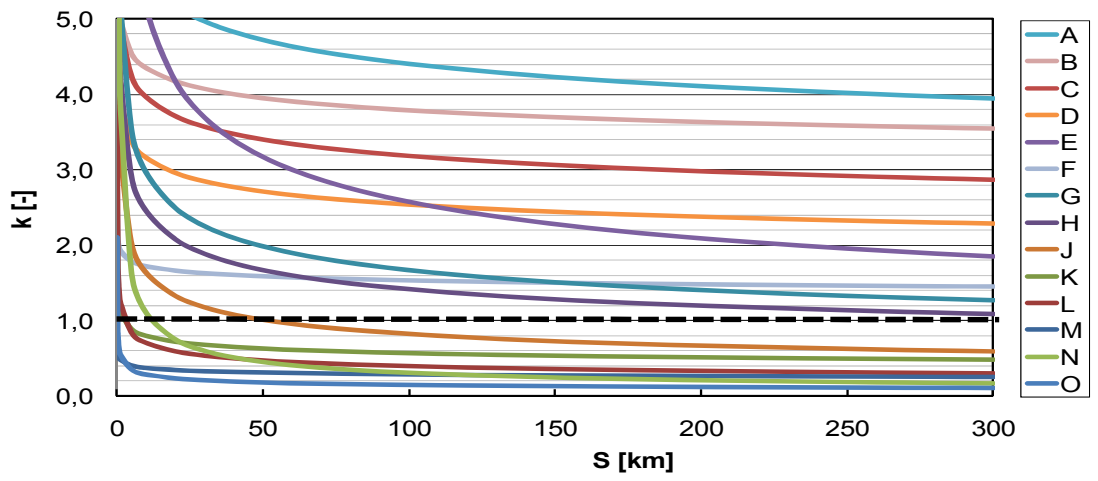

Figure 4: Curves of the exhaust emission indexes $[9,10]$. 


\section{Example of the application of research}

\subsection{Case study of sustainable development of the transport system with the EMITRANSYS model}

The EMITRANSYS model implemented in VISUM [1, 2] was used to simulation of multivariate distribution of the passenger and cargos on transport network. For the purposes of the research the estimation of emission of harmful compounds was carried out. Substances which were analysed are as follows: carbon monoxide $(\mathrm{CO})$, nitrogen oxides $\left(N \mathrm{~N}_{x}\right)$ and hydrocarbons $(\mathrm{HC})$.

The study included passenger vehicles, buses, vans and trucks, and rail transport vehicles (included to distribute passengers and cargo flow, but skipped during estimation of emissions of harmful compounds). Each group of vehicles is characterized by share of vehicles meeting specific emission standards. This structure of vehicle was used to handle flows of goods and passengers in the transport system of Poland for individual years - 2015, 2020 and 2025.

The results for the years 2015 and 2025 are shown graphically in Figs 5-6.

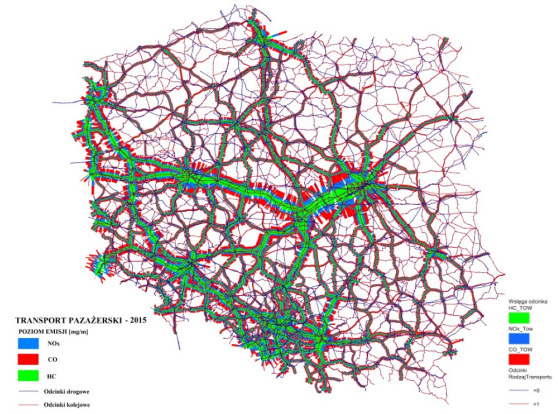

(a)

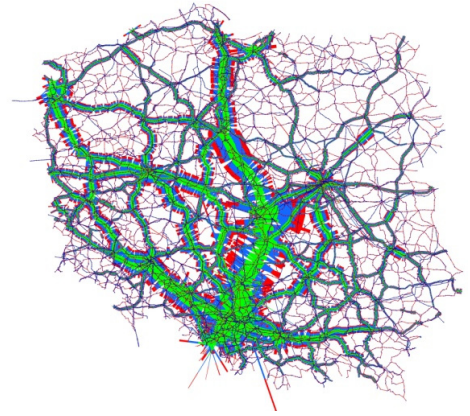

(b)

Figure 5: Emissions of harmful compounds of exhaust gases by passenger transport (a) and freight transport (b). Year of analysis: 2015 [2].

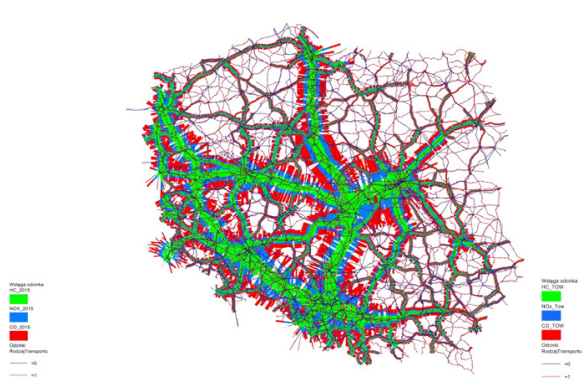

(a)

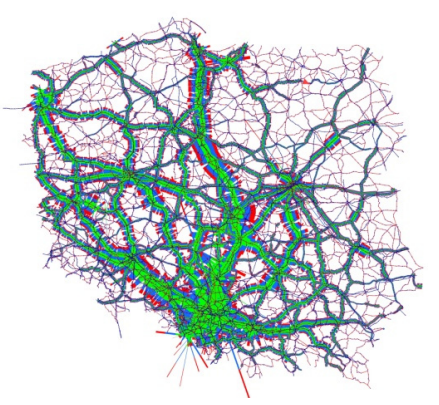

(b)

Figure 6: Emissions of harmful compounds of exhaust gases by passenger transport (a) and freight transport (b). Year of analysis: 2020 [2]. 


\subsection{Case study of the impact of eco-driving on carbon dioxide emissions from road vehicles in the city}

For measuring concentration of $\mathrm{CO}_{2}$ in the exhaust gases a portable system PEMS was used. The values of road emission of carbon dioxide were obtained as a result of the performance of road tests in the city of Poznan. The vehicle test route is shown in Fig. 7. The length of the route was about $15 \mathrm{~km}$. The route was diversified and included a typical urban portion and an extra-urban portion, where it was possible to drive with higher speeds $(70-80 \mathrm{~km} / \mathrm{h})$.

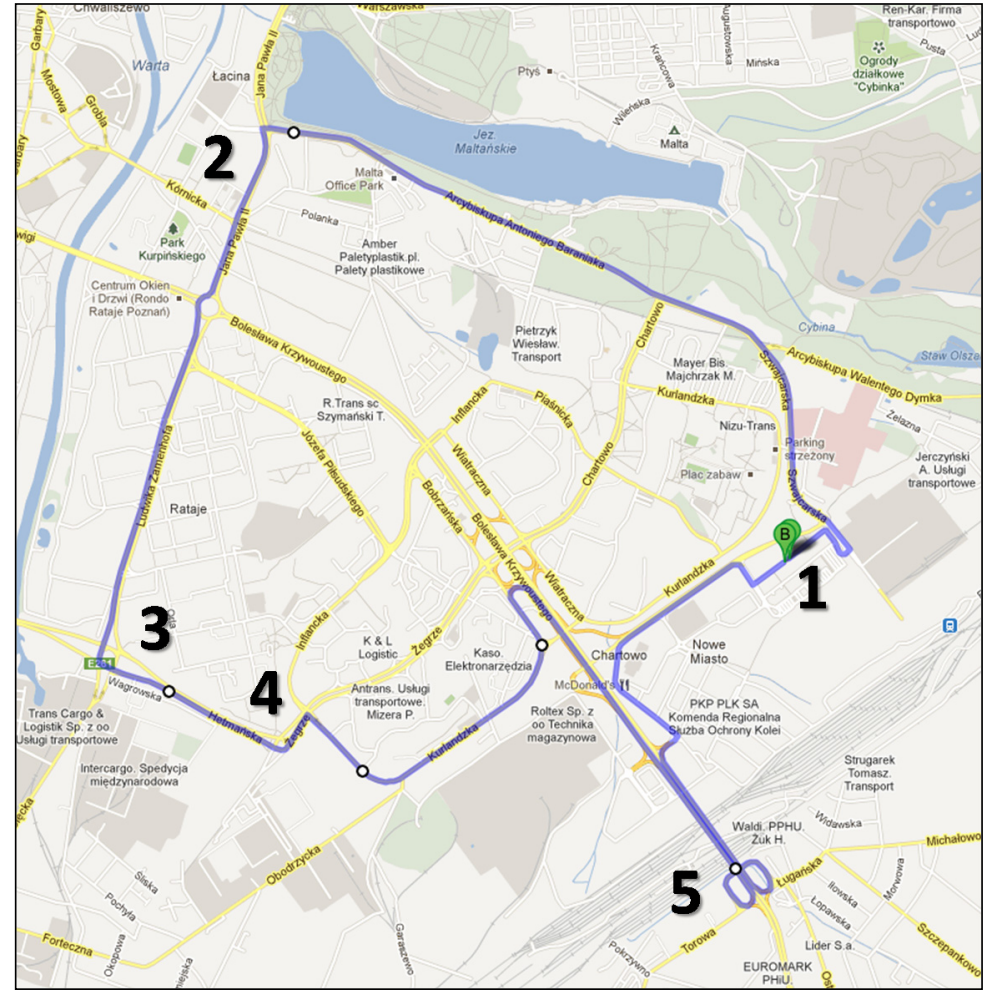

Figure 7: The test route located in Poznan $[9,10]$.

Due to the variability of the traffic parameters the route was divided into five measurement portions:

- urban traffic with high intensity - a large part of stoppage of the vehicle (approximately $4.5 \mathrm{~km}-30 \%$ of the tested route),

- urban traffic with low intensity $(2.5 \mathrm{~km}-16 \%$ of the tested route),

- extra urban traffic - expressway, speed limit of $70 \mathrm{~km} / \mathrm{h}(1 \mathrm{~km}-6 \%$ of the tested route),

- mixed traffic - part of the portion is an expressway, speed limit of $80 \mathrm{~km} / \mathrm{h}$ (approximately $4 \mathrm{~km}-26 \%$ of the tested route), 
- mixed traffic - part of the portion are internal roads (approximately $3 \mathrm{~km}$ $22 \%$ of the tested route).

During the test, driving conditions and concentrations of harmful substances of exhaust gases were measured in three test runs named, respectively: ecodriving, normal and aggressive. Definitions of particular driving styles are as follows:

- eco-driving - moderate acceleration, change of gear at $n=2000-2500 \mathrm{rpm}$, driving in the 5th gear if only possible, engine brake - reduction of gears while e.g. approaching traffic lights,

- normal - slow acceleration, change of gear at $\mathrm{n}=2500-3000 \mathrm{rpm}$, driving maximum in 4th gear, driving in neutral position of gearbox, (engine idling) while approaching e.g. traffic lights,

- aggressive - dynamic acceleration, change of gear at engine speed over 3000 rpm, driving maximum in 4th gear, approaching traffic lights - sharp braking from relatively high speed in the final phase of approaching.

Based on the measured concentration of carbon dioxide in exhaust gases, the intensity of its emission for all five measurement routes was calculated. Exemplary characteristics of carbon dioxide emissions intensity for one of the portions of the tested route are presented in Fig. 8 with two "extreme" driving styles.

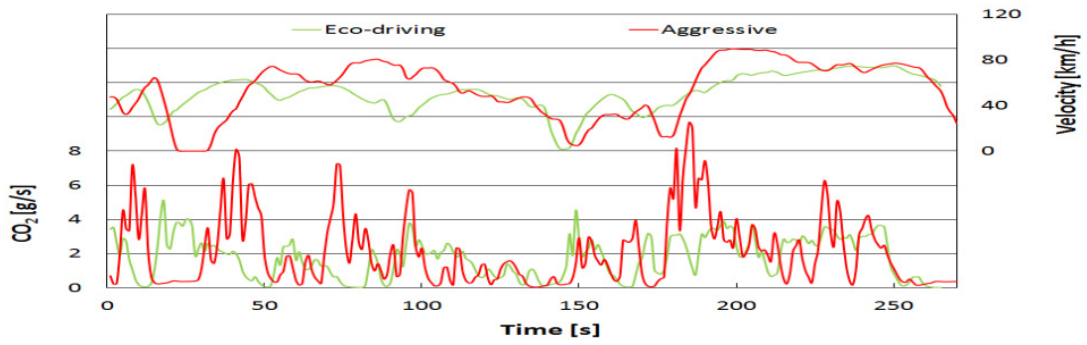

Figure 8: Emission intensity of carbon dioxide [9, 10].

Apart from determining the influence of the applied driving style on the emission of $\mathrm{CO}_{2}$ in the exhaust gases of the tested passenger car, also its influence on the fuel consumption was checked. The mileage fuel consumption value (expressed in $\mathrm{dm}^{3} / 100 \mathrm{~km}$ ) for the entire test route, against the average acceleration, is illustrated in Fig. 9.

\section{Conclusion}

Significant aspect of EMITRANSYS project was development of functional relations between level of emissions and technical parameters of vehicles as well as sub-technical factors like demand for transport (affecting vehicles capacity usage) or infrastructure conditions limiting velocity, or transshipment possibilities. 


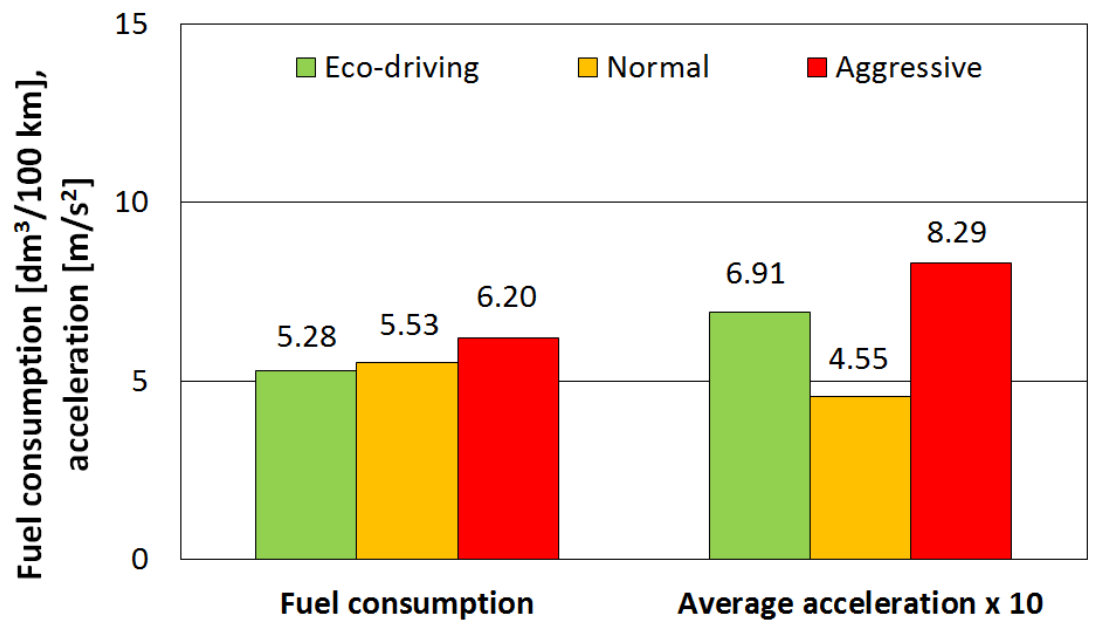

Figure 9: Fuel consumption specified for the entire test route $[9,10]$.

EMITRANSYS model uses indicators derived from real traffic measurements representing mathematically level of harmful emissions as a function of technical parameters of road infrastructure, as well as organizational functions and parameters of transport system maintenance. It can be used to simulation studies on the impact of road transport on the environment

The conducted road tests of passenger car in real conditions of its operation visualized significant influence of the driving style employed by a driver on the road emission of carbon dioxide and on the fuel consumption. A significant increase of road emissions values of this harmful substance should be pointed out for aggressive driving style and a noticeable decrease for ecological and economical driving style - so-called eco-driving.

It should be pointed out that the conducted tests were just introductory. In order to fully determine the influence of the manner of exploitation of vehicles on their ecological characteristics and energy consumption the test should cover bigger number of vehicles and the tests of toxicity of the exhaust gases should be conducted on routes with different characteristics, including motorway traffic.

\section{Acknowledgement}

This paper was prepared as a part of research project "Proecological transport system designing" (EMITRANSYS) funded by the National Centre for Research and Development.

\section{References}

[1] Jacyna M., Merkisz J.: Proecological approach to modelling traffic organization in national transport system, The Archives of Transport, issue 2/vol.30, 2014, pp. 31-41. 
[2] Jacyna M., Wasiak M.: Simulation model to support designing a sustainable national transport system, Index Copernicus International, ISBN 978-83-941338-0-1, Warsaw 2014.

[3] Jacyna M., Żak J., Jacyna-Gołda I., Merkisz J., Merkisz-Guranowska A., Pielecha J.: Selected Aspects of the Model of Proecological Transport System, Journal of Kones, Powertrain and Transport. Journal of KONES Powertrain and Transport, Warszawa 2013. Vol. 20, No. 3, str. 193-202.

[4] Merkisz-Guranowska, A., Merkisz, J., Kozak, M., Jacyna, M., Development of a sustainable road transport system, WIT Transactions on The Built Environment, Vol. 130, pp. 507-517, 2013.

[5] Żak, J., Lewczuk, K., Jacyna-Gołda, I., Jachimowski, R., Kłodawski, M. National Logistics Network Design with Regard to Transport CoModality. Logistics \& Transport. Vol. 19, No. 3, pp. 57-64, 2013.

[6] Jacyna M., Merkisz J.: The application possibilities of the evaluation of emissions from vehicles in real traffic conditions for proecological transport system designing (Part 1), Logistyka: ILiM, nr 4, 2014, ss. 1719.

[7] Jacyna M., Merkisz J.: The application possibilities of the evaluation of emissions from vehicles in real traffic conditions for proecological transport system designing (Part 2), w: Logistyka: ILiM, nr 5, 2014, ss. 14-17.

[8] Costabile, F., Allegrini, I., A new approach to link transport emissions and air quality: An intelligent transport system based on the control of traffic air pollution, Environmental Modelling \& Software 23, pp. 258-267, 2008.

[9] Merkisz, J., Andrzejewski, M., Wpływ eco-drivingu na emisje dwutlenku węgla z samochodu dostawczego, AUTOBUSY: Technika, Eksploatacja, Systemy Transportowe 3/3013, s. 193-202.

[10] Merkisz, J., Andrzejewski, M., Pielecha, J., Porównanie emisji dwutlenku węgla $\mathrm{W}$ rzeczywistych warunkach ruchu pojazdu $\mathrm{z}$ wartościami uzyskiwanymi w teście homologacyjnym na tle norm europejskich, Combustion Engines, No. 3/2011, s. 1-9.

[11] Vienneau, D., De Hoogh, K., Briggs, D., A GIS-based method for modelling air pollution exposures across Europe, Science of the Total Environment 408, pp. 255-266, 2009.

[12] Merkisz, J., Merkisz-Guranowska, A., Pielecha, J., Nowak, M., Jacyna, M., Lewczuk, K., Żak, J., Exhaust emission measurements in the development of sustainable road transport, Journal of KONES Powertrain and Transport, Vol. 20, No. 4, pp. 277-284, 2013.

[13] Jachimowski, R., Jacyna, I., Lewczuk, K., Functions of elements in the Logistics System of Poland. in: M. JACYNA (ed.) The Logistics System of Poland and transport co-modality, WUT Pub. Ho., Warsaw. pp. 68-90, 2011.

[14] Jacyna M., Wasiak M., Lewczuk K., Kłodawski M., Simulation model of transport system of Poland as a tool for developing sustainable transport, The Archives of Transport, issue 3/vol.31, 2014, pp. 23-35. 
[15] Lewczuk, K., Żak, J., Pyza, D., Jacyna-Gołda, I., Vehicle routing in urban area - environmental and technological determinants. WIT Transactions on The Built Environment, Vol. 130, pp. 373-384, 2013.

[16] Bai, S., Chiu, Y.-C.E. and Niemeier, D.A., A comparative analysis of using trip-based versus link-based traffic data for regional mobile source emissions estimation, Atmospheric Environment 41, pp. 7512-7523, 2007.

[17] Affum, J.K., Brown, A.L., Chan, Y.C., Integrating air pollution modelling with scenario testing in road transport planning: the TRAEMS approach, The Science of the Total Environment 312, pp. 1-14, 2003.

[18] Regulation (EC) No 510/2011 of the European Parliament and of the Council of 11 May 2011 setting emission performance standards for new light commercial vehicles as a part of the community's integrated approach to reduce $\mathrm{CO}_{2}$ emissions from light-duty vehicles, OJ L 145/1. 